\title{
Disorders of Water and Acid-Base Homeostasis
}

\author{
Fiona E. Karet \\ Department of Medical Genetics and Division of Renal Medicine, University of Cambridge, Cambridge, UK
}

\author{
Key Words \\ Nephrogenic diabetes insipidus • Renal tubular acidosis • \\ Renal tubule $\cdot$ Polarized epithelia
}

\begin{abstract}
Disorders of water balance lead either to dehydration or overhydration. Because there is an intimate relationship between water and sodium concentration (water generally following salt), one can distinguish hypotonic, isotonic and hypertonic dehydration and the same for overhydration. The vast majority of water balance disorders are acquired. In this article, the focus is on the inherited disorders both of water (nephrogenic diabetes insipidus) and acid-base balance. Both acidosis and alkalosis can arise from primary tubular ion transport abnormalities. The alkaloses are usually secondary to salt handling problems, whereas the renal tubular acidoses are often a consequence of primary abnormalities of acid-base transporters.

Copyright $\odot 2010$ S. Karger AG, Basel
\end{abstract}

\section{Water}

\section{Introduction}

Disorders of water balance lead either to dehydration or overhydration. Because there is an intimate relationship between water and sodium concentration (water generally following salt) one can distinguish hypotonic, isotonic and hypertonic dehydration and the same for overhydration.

The vast majority of water balance disorders are acquired. In the situation of overhydration, causes include excessive administration of salt-free solutions, psychogenic polydipsia, gastric lavage with water, increased $\mathrm{ADH}$ activity (e.g. postoperatively or in pain), liver failure, protein-losing enteropathy, drinking of sea water, overactivity of the renal cortex in Conn syndrome, Cushing syndrome, cerebral salt retention or administration of steroids. In oliguric or anuric states (cardiac failure, nephrotic syndrome, chronic uraemia or acute glomerulonephritis) overhydration is of course much more easily achieved.

In the case of dehydration, the clinical picture may involve simple inadequate water intake, GI losses, sweating, adrenal failure, adrenalectomy, drainage of ascites, peritonitis, burns, sedative or carbon monoxide intoxication, sunstroke, cerebral salt wasting, the polyuric phase of acute kidney injury, some chronic nephropathies, chronic diuretic therapy or diabetes insipidus (DI).

DI arises either because of abnormalities of the antidiuretic hormone arginine vasopressin itself (AVP, OMIM 192340), known as central or cranial DI, or because of inability of the kidney to respond to AVP by appropriately conserving water (nephrogenic DI, NDI) [1]. The latter may be drug-related (e.g. lithium), or primary (inherited). Primary cranial DI is dominantly inherited. It responds to administration of AVP analogues such as

\section{KARGER}

() 2010 S. Karger AG, Basel

Fax +4161306 1234

E-Mail karger@karger.ch

www.karger.com
Accessible online at: www.karger.com/nep
Fiona E. Karet

Cambridge Institute for Medical Research

Box 139, Addenbrooke's Hospital, Hills Road

Cambridge, CB2 OXY (UK)

Tel. +44 1223762 617, Fax +44 1223331 206, E-Mail fek1000@ cam.ac.uk 


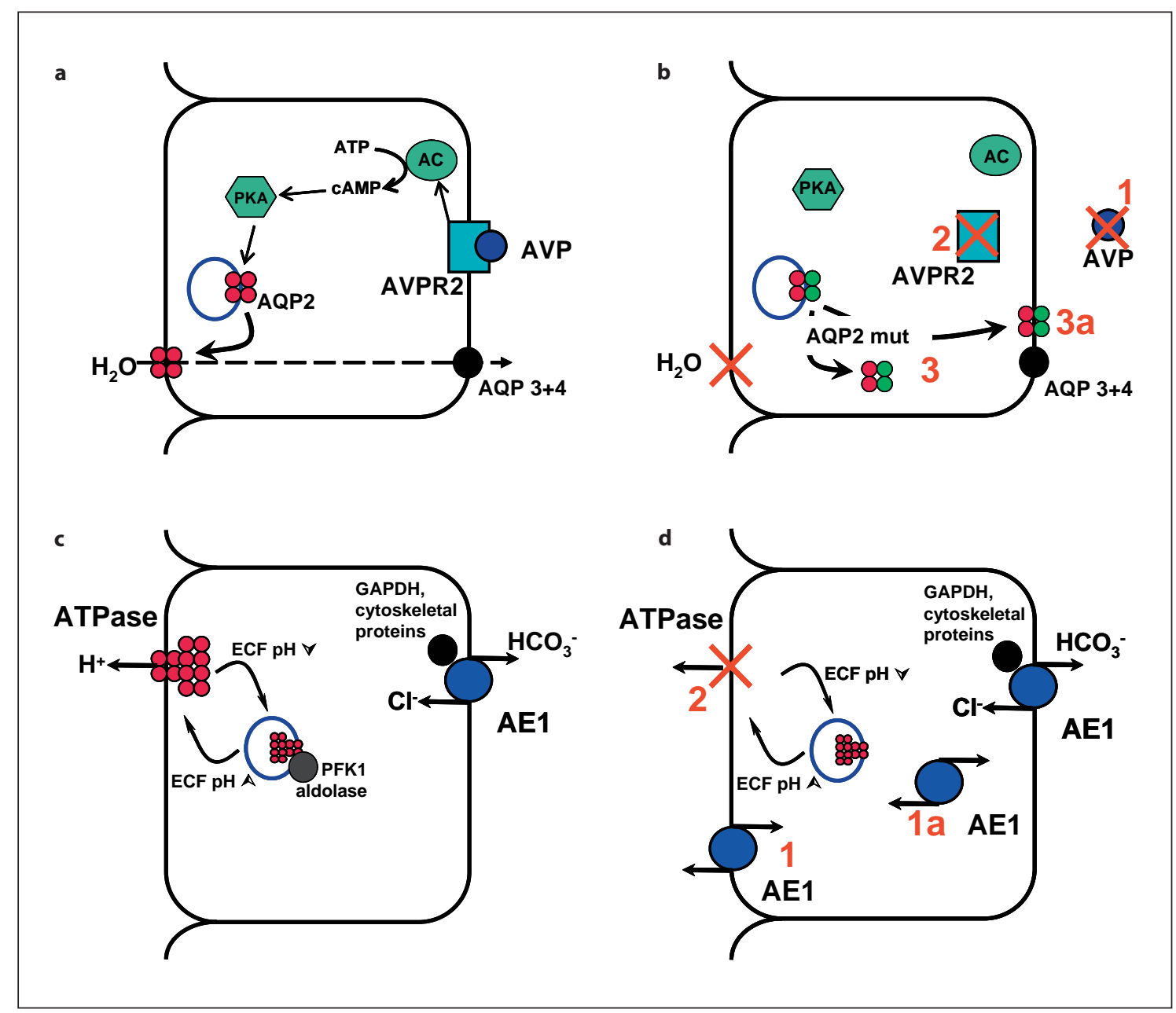

Fig. 1. Mechanisms of disease in disorders of water balance (a, b) and acid (c, d). Normal polarized principal (a) and $\alpha$-intercalated (c) renal tubular cells are depicted on the left. Corresponding cells b and $\mathbf{d}$ illustrate single-gene defects. a The pituitary hormone AVP binds on the basolateral side of the principal cell to its receptor (AVPR2), and institutes a signalling cascade involving adenylyl cyclase and PKA that results in insertion of AQP2 water channels into the apical membranes, allowing water uptake. b Central DI is due to failure of AVP itself (1), while NDI can be X-linked due to mutations in the AVPR2 gene (2) or autosomal in association with AQP2 mutations. Mutant AQP2 may be intracellularly retarded and degraded (3), or mis-targeted (3a). c Systemic pH is finely tuned by the coupled function in $\alpha$-intercalated cells of the apical $\mathrm{H}^{+} \mathrm{ATP}$ ase and the basolateral chloride-bicarbonate exchanger AE1. Each has a number of binding partners as shown. Both $\mathrm{H}^{+}$ATPase and AE1 recycle between intracellular and membrane location depending on ambient $\mathrm{pH}$ (only $\mathrm{H}^{+} \mathrm{ATPase}$ illustrated). d Dominant dRTA can result from mistargeting or dominant negative retention of mutant $\operatorname{AE} 1(1,1 \mathrm{a})$, while recessive disease is due to loss of $\mathrm{H}^{+}$ATPase because of mutations in either the B1 or a4 subunit of the pump (2).
DDAVP and will not be discussed further here. Within the renal tubule, the principal cell is the one responsible for regulation of water balance (fig. 1a).

\section{Primary NDI}

Clinical Features

Recessive NDI classically presents in early infancy with severe dehydration, accompanied by hypernatrae- mia and often, hyperthermia, failure to thrive, vomiting and/or constipation. However, the significance of nonspecific symptoms in infants may go unrecognized for months to years and a high index of suspicion is necessary. Repeated episodes of dehydration can lead to intellectual impairment. Administration of DDAVP has no effect. In contrast, the dominantly inherited form presents later, with less marked dehydration. 
Any polyuric state can result in dilatation of the urinary tract and/or bladder, and this is a common feature on imaging. If patients cannot learn to void the bladder frequently, renal impairment can supervene.

Genes and Their Functional Consequences

NDI may be due to defects in the AVP receptor (AVPR2, OMIM 300538) or the water channel aquaporin 2 (AQP2, OMIM 107777). The gene encoding AVPR2 resides on the $\mathrm{X}$ chromosome, and inheritance is therefore $\mathrm{X}$-linked recessive. In contrast, disease associated with $A Q P 2 \mathrm{mu}-$ tations may be autosomal recessive or dominant, the gene being found on chromosome 12. Overall, NDI is rare, with prevalence of AVPR2-related disease estimated at 1:100,000 [2], recessive AQP2 tenfold less prevalent than this and dominant AQP2 disease reported in only a handful of kindreds worldwide [3].

Severe manifestations of X-linked NDI are usually confined to males, carrier females being spared. However, skewed X-inactivation may lead to females being as badly affected as their male counterparts [4]. Normal water reabsorption relies on the maintenance of normal epithelial polarity with AQP2 on the urinary (apical) surface, and AVPR2 basolateral (fig. 1a). The cellular mechanisms involved in NDI are therefore of interest.

AVPR2: At least half of the mutations in AVPR2 are missense changes $[2,5]$. The vast majority of mutations investigated are intracellularly retarded, and do not make it to the basolateral cell surface [6] (fig. 1b). This is a common fate of misfolded proteins, and in this case probably leads to accelerated degradation rather than toxic accumulation, since other principal cell functions appear preserved. Intriguingly, Bernier et al. [7] went on to show that normal cellular trafficking could be restored by administration of selective non-peptide antagonists, and proof-of-principle was obtained in a small number of patients. A small number of mutations in AVPR2 lead to partial insensitivity to AVP, and here the age of onset is higher and phenotype milder, much like dominant AQP2 disease (see below).

AQP2: This six-transmembrane-domain protein functions as a tetramer, which assembles in the endoplasmic reticulum [8]. Most mutations cluster in the gene segment encoding the transmembrane domain. AQP2 requires AVP-stimulated shuttling to the apical surface for functional integrity. The majority of mutants in recessive disease are misfolded and therefore ER retained and degraded, as with AVPR2-related NDI. However, in dominant disease, two other mechanisms have been identified: the mutant protein may either be missorted to late endo- somes/lysosomes and degraded there, or missorted to the basolateral surface [reviewed in 3] (fig. 1b).

\section{Management}

Adequate water replacement is a cornerstone of management of NDI, whatever the cause, and unrestricted access to potable water must be ensured. However, since infants cannot obtain fluids voluntarily, extra care must be taken including at night. Affected individuals may also not be able to cope with the required volumes. Dietary salt reduction is a useful accompaniment, as is administration of a thiazide. The thiazide acts by diminishing free water loss that accompanies sodium reabsorption. Amiloride or spironolactone may be a useful adjunct to limit distal sodium reabsorption. NSAIDs may also be useful.

\section{How Genetics Fits into Clinical Care}

Bichet has made an impassioned plea for testing of all infants suspected of having recessive NDI, since correct diagnosis facilitates prompt institution of treatment, which he argues is both effective and avoids complications [9]. Although severely affected girls are unlikely to harbour AVPR2 mutations, a negative AQP2 screen should prompt reassessment. At-risk newborn siblings of affected individuals can reasonably be put forward for testing. The GeneTests website http://www.ncbi.nlm.nih. gov/sites/GeneTests/lab?db=GeneTests offers information on labs testing either gene.

\section{Acid}

\section{Introduction}

Both acidosis and alkalosis can arise from primary tubular ion transport abnormalities. The alkaloses are usually secondary to salt handling problems and are covered elsewhere in this special edition. The term 'renal tubular acidosis' (RTA) usually refers to systemic acidosis arising from either acid or bicarbonate transporter defects [10]. The kidney plays a key role in the regulation of acid-base balance, as it can vary bicarbonate reclamation and net acid excretion such that urine $\mathrm{pH}$ can range from about 4.5 to over 8 . On a mixed omnivorous diet, humans produce a net acid load of about $1 \mathrm{mmol} / \mathrm{kg} / \mathrm{day}$, which must be excreted via the urine. Through activity at two main sites in the nephron, the proximal convoluted tubule and the collecting duct (via the $\alpha$-intercalated cell; fig. 1c), systemic $\mathrm{pH}$ is closely maintained at $7.4 \pm 0.04$, and the unwanted acid is re- 
moved. Failure of these tubular functions can cause very severe acidosis with $\mathrm{pH}<7.2$.

The RTAs are best classified using a 'geographical' division as follows:

- Proximal

- Distal, subdivides into classic and hyperkalaemic

- Mixed (usually refers to carbonic anhydrase deficiency).

As with DI, dominantly inherited acidosis is generally clinically milder and is usually due to gain of abnormal function of a channel or transporter, while loss of function genetic defects are more severe and likely to be recessive. In general, both proximal and distal RTAs are most commonly acquired: proximal in association with drugs or myeloma, and distal in association with autoimmune conditions such as Sjögren's (classic) or any form of hyporeninaemic hypoaldosteronism (hyperkalaemic). In inherited hyperkalaemic RTA, the primary diagnosis is related to salt handling (e.g. Gordon syndrome). The remainder of this article is devoted to the primary RTAs.

While all the recessive diseases described here are rare, they arise more often in communities when consanguinity is prevalent. The investigation of kindreds where affected children are the offspring of consanguineous union of unaffected parents has provided a powerful tool to discover the genetic causes of both recessive acid and water-handling disorders, and to understand better the molecular pathophysiology involved.

\section{Proximal RTA}

Clinical Features

In most cases, proximal RTA is part of a bigger renal Fanconi syndrome that includes one or more of the other features of proximal tubular dysfunction such as tubular proteinuria, hypophosphataemia, glycosuria, hypouricaemia, vitamin D deficiency. There is an abnormally low renal threshold for bicarbonate reabsorption, and bicarbonate levels in the mid-teens are to be expected. Urinary acidification capacity should be unimpaired.

A number of drugs are also associated with proximal RTA, especially anticancer and anti-HIV therapies. Onset of the inherited forms is usually in childhood, and nephrocalcinosis may be associated. Cystinosis and Lowe syndrome are good examples, and in both, ocular involvement, intellectual impairment and poor muscle tone are also prominent. Very rarely indeed, proximal RTA is a primary condition (OMIM 604278), associated with mental retardation, ocular 'band' keratopathy, cataracts, glaucoma, and short stature [11].

Disorders of Water and Acid-Base Homeostasis
Genes and Their Functional Consequences

Primary pRTA is associated with recessive mutations in SLC4A4, which encodes the proximal tubule's major basolateral sodium bicarbonate transporter [11]. Lowe syndrome is associated with mutations in the OCRL1 gene (OMIM 300535) [12], which encodes one of the family of inositol polyphosphate-5-phosphatases. Interestingly, mutations in this gene can also cause Dent disease (OMIM 300009), where the phenotype includes renal tract calcification and chronic kidney disease, but acidosis is not a prominent feature [13]. In contrast, cystinosis is associated with defects in the lysosomal protein cystinosin (OMIM 606272, 219900) [14], which leads to cell toxicity because of lysosomal accumulation of cystine.

\section{Management}

Proximal RTA may on the face of it require a large amount of bicarbonate replacement, because renal losses are much greater than in distal disease. However, this can lead to a vicious cycle of bicarbonate diuresis. In this respect, thiazides may offer apparently paradoxical help as the consequent volume depletion may promote bicarbonate reabsorption to some degree. $\mathrm{K}^{+}$supplements and vitamin D may be necessary.

\section{How Genetics Fits into Clinical Care}

It is important to determine an accurate clinical and genetic diagnosis, as the prognosis for and management of the different forms of renal Fanconi syndrome may not be identical. It is also important for empowerment of patients and their families, and to permit ongoing care to be handled by physicians with expertise and interest in the relevant rare condition.

\section{Dominant Distal RTA}

\section{Clinical Features}

The clinical spectrum in dominant or sporadic distal RTA is wide, ranging from spontaneous metabolic acidosis and severe stone formation with growth retardation and rickets/osteomalacia, to an occult ('compensated') acidosis with incidental findings of nephrocalcinosis. The biochemical hallmark is inability of the kidneys to acidify the urine appropriately - a urine $\mathrm{pH}$ of $>5.5$ is often taken as the cut-off, whether in the context of spontaneous acidosis or following an oral acid challenge. The renal stones are explained by a combination of hypercalciuria, low urinary citrate levels (secondary to up-regulation of citrate reabsorption by the proximal tubule in acidosis) and high urine $\mathrm{pH}$, all of which will favour calcium phosphate stone formation. Hypokalaemia, another

Nephron Physiol 2011;118:p28-p34 p31 
characteristic feature, is usually less severe in inherited vs. acquired forms of distal RTA, but can be troublesome, especially if a thiazide diuretic is prescribed to reduce hypercalciuria. Primary dominant dRTA is rare, with only tens of kindreds/cases reported in the literature.

\section{Genes and Their Functional Consequences}

All reported cases of dominant dRTA are attributable to a single gene: $S L C 4 A 1$, which encodes the collecting duct's basolateral anion exchanger AE1 (also known as Band-3 from its appearance on red cell membrane protein analysis by gel electrophoresis) [15]. Although the same gene encodes both the red cell and the slightly shorter kidney isoform of AE1, there is no overlap between the two potential phenotypes of spherocytosis/ ovalocytosis and dRTA, apart from rare co-dominant or recessive cases from Southeast Asia [16]. There is a 'hotspot' for dRTA mutations at residue R589, which may be related to the presence of $\mathrm{CpG}$ di-nucleotides on both strands. In all the substitutions, $\mathrm{C}$ is replaced by $\mathrm{T}$, which can arise as a result of endogenous methylation and spontaneous deamination [17].

Haploinsufficiency is likely in the red cell dysmorphic disorders associated with SLC4A1, but given the nonoverlapping clinical picture, this cannot be the explanation for dominant dRTA, particularly since xenopus oocyte expression of various mutants has demonstrated normal or only mildly impaired anion exchange function $[15,18]$. Instead, it has been shown that the mutant AE1 proteins are mistargeted in polarized cells, either by being retained (probably along with wild-type) intracellularly, or appearing at the inappropriate apical surface (fig 1d). The latter is an unusual mechanism of disease and has been best studied in a C-terminal truncating mutant (R901X) [19, 20].

\section{Management}

One to $3 \mathrm{mmol} / \mathrm{kg} / \mathrm{day}$ of bicarbonate supplementation should be sufficient to maintain venous bicarbonate at the low end of the normal range, and can be expected to heal thinned bones, to prevent stones and to limit progression of nephrocalcinosis. Potassium citrate is probably preferable to sodium bicarbonate, as hypokalaemia is dealt with concurrently, and the additional sodium load is unnecessary and may worsen hypercalciuria.

\section{How Genetics Fits into Clinical Care}

The classical biochemical ways to diagnose dominant dRTA are either to observe urine alkalinity (meter reading of fresh urine, not dipstick) in the presence of normal anion gap metabolic acidosis, or for the patient to fail a urine acidification test. The 'gold standard' test for the past half-century has been the ammonium chloride $\left(\mathrm{NH}_{4} \mathrm{Cl}\right)$ loading test, where $100 \mathrm{mg} / \mathrm{kg}$ oral $\mathrm{NH}_{4} \mathrm{Cl}$ should under normal circumstances reduce urine $\mathrm{pH}$ to $<5.5$ over the next $8 \mathrm{~h}$. However, $\mathrm{NH}_{4} \mathrm{Cl}$ is unpleasant to consume, and the combination of a single dose of $1 \mathrm{mg}$ fludrocortisone and $40 \mathrm{mg}$ furosemide have been proposed to yield the same effect on urine $\mathrm{pH}$ [21]. Where autoimmunity has been ruled out, or where there is a positive family history, sequencing of SLC4A1 can be performed. This is also useful in view of the variable penetrance evidenced by compensated acidosis in some individuals, even within the same family [22]. All reported mutations to date have arisen in exons 14, 15 or 20.

\section{Recessive Distal RTA}

\section{Clinical Features}

The phenotypic spectrum in recessive dRTA is towards the more severe end, usually affecting children. In its severest form, affected infants with type 1 RTA fail to thrive and are very acidotic and volume depleted, with marked hypokalaemia but otherwise normal renal excretory function. Calcium and phosphate are usually normal. Growth is poor, and rickets is common in untreated cases, both because of leaching of mineral from bone in an attempt to buffer the acidosis, and because bone resorption by osteoclasts is increased in acidosis. Nephrocalcinosis may be observed from a very early age, and may lead to accelerated renal impairment. As with dominant disease, urinary citrate is low, and hypercalciuria and hypokalaemia may be prominent.

The majority of these children also develop progressive sensorineural hearing loss, which does not respond to treatment. The explanation for some children retaining their hearing is not clear.

\section{Genes and Their Functional Consequences}

Recessive dRTA is heterogeneous, and to date two genes have been implicated: ATP6V1B1 and ATP6V0A4 $[23,24]$. Both encode different subunits of the vacuolartype $\mathrm{H}^{+}$ATPase, and in both cases the subunit proteins are variants of the 'generic' form found ubiquitously in all such proton pumps, both having a much restricted tissue distribution. In both cases, the kidney, male genital tract and inner ear are the main sites of expression. A few families have been reported who are unlinked to either locus [24].

The majority of reported mutations are predicted to be highly disruptive to the apical proton pump, as they are 
frameshifts, nonsense or splice junction changes that would disrupt the relevant subunit protein and preclude pump assembly (fig. 1d). Some point mutations have also been studied, with the suggestion that mutant subunits can make their way solo to the apical membrane [25]. In terms of disease severity, no real genotype-phenotype correlation has been established, apart from the observation that in general, a 4 homozygotes have hearing that is less severely affected than with loss of B1 [26]. It is only a4 patients who have to date been reported to have preserved hearing into adulthood [23]. Conversely however, both a4 and B1 loss can lead to early deafness [27] In addition, cranial imaging may reveal a widened vestibular aqueduct [28], a feature of other ion channelopathies such as Pendred syndrome.

\section{Management}

As with dominant disease, relatively low does of citrate/bicarbonate replacement are often sufficient on their own for all but the hearing component. Anatomical isolation of the inner ear and irreplaceability of hair cells underlie the progressive nature of the hearing loss. In severe cases, cochlear implantation may be indicated [28], and if deafness is of early onset, assistance with speech and language may be important. Whatever the genetic cause, ongoing assessment and appropriate educational assistance should be mandatory.

\section{How Genetics Fits into Clinical Care}

In recessive disease the phenotype is usually reasonably easy to discern by examination of the patient, radiology and biochemistry. The hearing status is not sufficient to differentiate between ATP6V1B1 and ATP6V0A4. Gene screening is available as a research and diagnostic tool, some labs offering commercial testing (see GeneTests). This may include prenatal testing, particularly in families that have experienced deaths of affected children.

\section{'Mixed' RTA}

\section{Clinical Features}

The clinical features of primary mixed RTA are those of osteopetrosis (OP) combined with acidosis: usually within the first 2 years of life fractures, short stature, mental retardation, dental malocclusion, and visual impairment from optic nerve compression become evident, with later intracranial calcification. This is also known as Guibaud-Vainsel syndrome or marble brain disease (OMIM 259730). The acidosis may limit the degree of bone thickening, but increased density is usually readily

evident on plain X-ray. It should be noted that some OP patients have only distal RTA. A milder phenotype may also sometimes be observed.

\section{Genes and Their Functional Consequences}

Classical OP is caused by loss of function of carbonic anhydrase $2[29,30]$, which has high expression in osteoclasts of bone and in both proximal and distal tubule. Failure of bone remodelling via osteoclasts accounts for the thickened but fragile bones. A phenocopy of CA2 disease was identified in a consanguineous kindred where homozygosity for loss-of-function of both ATP $6 V 0 A 3$ (which encodes the osteoclast-specific form of the proton pump's a-subunit) and the renal $\mathrm{H}^{+} \mathrm{ATPase} \mathrm{B} 1$ subunit gene discussed in 'Recessive Distal RTA, Genes and Their Functional Consequences' were found [31].

\section{Management}

The only way to replace CA2 is to perform bone marrow transplantation, but this of course does not affect the RTA, which requires bicarbonate supplementation and may require vitamin $\mathrm{D}$.

\section{How Genetics Fits into Clinical Care}

Generally, the phenotype is accounted for by CA2 mutations, and finding low levels in red cells can confirm this biochemically. However, care must be exercised as some mutations allow partial residual CA2 function [32].

\section{Acknowledgements}

F.E.K. is supported by the Wellcome Trust and the NIHR Cambridge Biomedical Research Centre.

References

Nephron Physiol 2011;118:p28-p34 71. 1054.
1 Makaryus AN, McFarlane SI: Diabetes insipidus: diagnosis and treatment of a complex disease. Cleve Clin J Med 2006;73:65-

2 Arthus MF, Lonergan M, Crumley MJ, Naumova AK, Morin D, De Marco LA, Kaplan BS, Robertson GL, Sasaki S, Morgan K, Bichet DG, Fujiwara TM: Report of 33 novel AVPR2 mutations and analysis of $117 \mathrm{fami}-$ lies with X-linked nephrogenic diabetes insipidus. J Am Soc Nephrol 2000;11:1044-

3 Deen PM, Van Os $\mathrm{CH}$, Knoers NVAM: Nephrogenic diabetes insipidus: aquaporin-2 defect; in Lifton RP, Somlo S, Giebisch GH, Seldin DW (eds): Genetic Diseases of the Kidney. Burlington, Academic Press, 2009, pp 351-362. 
-4 Nomura Y, Onigata K, Nagashima T, Yutani S, Mochizuki H, Nagashima K, Morikawa A: Detection of skewed X-inactivation in two female carriers of vasopressin type 2 receptor gene mutation. J Clin Endocrinol Metab 1997;82:3434-3437.

5 Bichet DG, Birnbaumer M, Lonergan M, Arthus MF, Rosenthal W, Goodyer P, Nivet H, Benoit S, Giampietro P, Simonetti S, et al: Nature and recurrence of AVPR2 mutations in X-linked nephrogenic diabetes insipidus. Am J Hum Genet 1994;55:278-286.

6 Morello JP, Salahpour A, Laperrière A, Bernier V, Arthus MF, Lonergan M, Petäjä-Repo U, Angers S, Morin D, Bichet DG, Bouvier M: Pharmacological chaperones rescue cellsurface expression and function of misfolded V2 vasopressin receptor mutants. J Clin Invest 2000;105:887-895.

7 Bernier V, Morello JP, Zarruk A, Debrand N, Salahpour A, Lonergan M, Arthus MF, Laperrière $A$, Brouard $R$, Bouvier $M$, Bichet DG: Pharmacologic chaperones as a potential treatment for X-linked nephrogenic diabetes insipidus. J Am Soc Nephrol 2006;17: 232-243.

8 Hendriks G, Koudijs M, van Balkom BW, Oorschot V, Klumperman J, Deen PM, van der Sluijs P: Glycosylation is important for cell surface expression of the water channel aquaporin-2 but is not essential for tetramerization in the endoplasmic reticulum. J Biol Chem 2004;279:2975-2983.

9 Bichet D: Nephrogenic diabetes insipidus: vasopressin receptor defect; in Lifton RP, Somlo S, Giebisch GH, Seldin DW (eds): Genetic Diseases of the Kidney. Burlington, Academic Press, 2009, pp 341-349.

10 Laing CM, Unwin RJ: Renal tubular acidosis. J Nephrol 2006;19(suppl 9):S46-S52.

-11 Igarashi T, Inatomi J, Sekine T, Cha SH, Kanai $\mathrm{Y}$, Kunimi M, Tsukamoto K, Satoh $\mathrm{H}$, Shimadzu M, Tozawa F, Mori T, Shiobara M, Seki G: Endou H: Mutations in SLC4A4 cause permanent isolated proximal renal tubular acidosis with ocular abnormalities. Nat Genet 1999;23:264-265.

$\checkmark 12$ Attree O, Olivos IM, Okabe I, Bailey LC, Nelson DL, Lewis RA, McInnes RR, Nussbaum RL: The Lowe's oculocerebrorenal syndrome gene encodes a protein highly homologous to inositol polyphosphate-5-phosphatase. Nature 1992;358:239-242.

-13 Hoopes RR Jr, Shrimpton AE, Knohl SJ, Hueber P, Hoppe B, Matyus J, Simckes A, Tasic V, Toenshoff B, Suchy SF, Nussbaum RL, Scheinman SJ: Dent disease with mutations in OCRL1. Am J Hum Genet 2005;76:260267.
14 Town M, Jean G, Cherqui S, Attard M, Forestier L, Whitmore SA, Callen DF, Gribouval O, Broyer M, Bates GP, van't Hoff W, Antignac C: A novel gene encoding an integral membrane protein is mutated in nephropathic cystinosis. Nat Genet 1998;18:319324.

15 Bruce LJ, Cope DL, Jones GK, Schofield AE, Burley M, Povey S, Unwin RJ, Wrong O, Tanner MJ: Familial distal renal tubular acidosis is associated with mutations in the red cell anion exchanger (band 3, AE1) gene. J Clin Invest 1997;100:1693-1707.

16 Wrong O, Bruce LJ, Unwin R, Toye AM, Tanner MJ: Band 3 mutations, distal renal tubular acidosis, and Southeast Asian ovalocytosis. Kidney Int 2002;62:10-19.

17 Duncan BK, Miller JH: Mutagenic deamination of cytosine residues in DNA. Nature 1980;2 87:560-561.

18 Rungroj N, Devonald MA, Cuthbert AW, Reimann F, Akkarapatumwong V, Yenchitsomanus PT, Bennett WM, Karet FE: A novel missense mutation in AE1 causing autosomal dominant distal renal tubular acidosis retains normal transport function but is mistargeted in polarized epithelial cells. J Biol Chem 2004;279:13833-13838.

19 Devonald MA, Smith AN, Poon JP, Ihrke G, Karet FE: Non-polarized targeting of AE1 causes autosomal dominant distal renal tubular acidosis. Nat Genet 2003;33:125-127.

20 Toye AM, Banting G, Tanner MJ: Regions of human kidney anion exchanger 1 (kAE1) required for basolateral targeting of kAE1 in polarised kidney cells: mis-targeting explains dominant renal tubular acidosis (dRTA). J Cell Sci 2004;117:1399-1410.

21 Schwartz GJ: Diagnosis of distal renal tubular acidosis: use of furosemide plus fludrocortisone versus ammonium chloride. Nat Clin Pract Nephrol 2007;3:590-591.

-22 Györy AZ, Edwards KD: Renal tubular acidosis. A family with an autosomal dominant genetic defect in renal hydrogen ion transport, with proximal tubular and collecting duct dysfunction and increased metabolism of citrate and ammonia. Am J Med 1968;45: $43-62$.

23 Smith AN, Skaug J, Choate KA, Nayir A, Bakkaloglu A, Ozen S, Hulton SA, Sanjad SA, Al-Sabban EA, Lifton RP, Scherer SW Karet FE: Mutations in ATP6N1B, encoding a new kidney vacuolar proton pump 116-kD subunit, cause recessive distal renal tubular acidosis with preserved hearing. Nat Genet 2000;26:71-75.

24 Karet FE, Finberg KE, Nelson RD, Nayir A, Mocan H, Sanjad SA, Rodriguez-Soriano J, Santos F, Cremers CRW, Di Pietro A, Hoffbrand BI, Winiarski J, Bakkaloglu A, Ozen S, Dusunsel R, Goodyer P, Hulton SA, Wu DK, Skvorak AB, Morton CC, Cunningham MJ, Jha V, Lifton RP: Mutations in the gene encoding the $\mathrm{B} 1$ subunit of $\mathrm{H}^{+}$-ATPase cause renal tubular acidosis with sensorineural deafness. Nat Genet 1999;21:84-90.
25 Fuster DG, Zhang J, Xie XS, Moe OW: The vacuolar-ATPase B1 subunit in distal tubular acidosis: novel mutations and mechanisms for dysfunction. Kidney Int 2008;73: 1151-1158.

26 Stover EH, Borthwick KJ, Bavalia C, Eady N, Fritz DM, Rungroj N, Giersch AB, Morton CC, Axon PR, Akil I, Al-Sabban EA, Baguley DM, Bianca S, Bakkaloglu A, Bircan Z, Chauveau D, Clermont MJ, Guala A, Hulton SA, Kroes H, Li Volti G, Mir S, Mocan H, Nayir A, Ozen S, Rodriguez Soriano J, Sanjad SA, Tasic V, Taylor CM, Topaloglu R, Smith AN, Karet FE: Novel ATP6V1B1 and ATP6V0A4 mutations in autosomal recessive distal renal tubular acidosis with new evidence for hearing loss. J Med Genet 2002;39:796803.

27 Vargas-Poussou R, Houillier P, Le Pottier N, Strompf L, Loirat C, Baudouin V, Macher MA, Déchaux M, Ulinski T, Nobili F, Eckart P, Novo R, Cailliez M, Salomon R, Nivet H, Cochat P, Tack I, Fargeot A, Bouissou F, Kesler GR, Lorotte S, Godefroid N, Layet V, Morin G, Jeunemaître X, Blanchard A: Genetic investigation of autosomal recessive distal renal tubular acidosis: evidence for early sensorineural hearing loss associated with mutations in the ATP6V0A4 gene. J Am Soc Nephrol 2006;17:1437-1443.

28 Joshua B, Kaplan DM, Raveh E, Lotan D, Anikster Y: Audiometric and imaging characteristics of distal renal tubular acidosis and deafness. J Laryngol Otol 2008;122:193-198.

29 Sly WS, Hewett-Emmett D, Whyte MP, Yu Y-SL, Tashian RE: Carbonic anhydrase II deficiency identified as the primary defect in the autosomal recessive syndrome of osteopetrosis with renal tubular acidosis and cerebral calcification. Proc Natl Acad Sci 1983; 80:2752-2756.

-30 Roth DE, Venta PJ, Tashian RE, Sly WS: Molecular basis of human carbonic anhydrase II deficiency. Proc Natl Acad Sci USA 1992;89: 1804-1808.

31 Borthwick KJ, Kandemir N, Topaloglu R, Kornak U, Bakkaloglu A, Yordam N, Ozen S, Mocan H, Shah GN, Sly WS, Karet FE: A phenocopy of CAII deficiency: a novel genetic explanation for inherited infantile osteopetrosis with distal renal tubular acidosis. J Med Genet 2003;40:115-121.

-32 McMahon C, Will A, Hu P, Shah GN, Sly WS, Smith OP: Bone marrow transplantation corrects osteopetrosis in the carbonic anhydrase II deficiency syndrome. Blood 2001;97: 1947-1950. 